\title{
Publisher Correction: Evidence for mid-Holocene rice domestication in the Americas
}

Lautaro Hilbert, Eduardo Góes Neves, Francisco Pugliese, Bronwen S. Whitney (ID, Myrtle Shock, Elizabeth Veasey, Carlos Augusto Zimpel and José Iriarte (iD

Correction to: Nature Ecology \& Evolution https://doi.org/10.1038/s41559-017-0322-4, published online 9 October 2017.

In the HTML version of this Article originally published, Fig. 4 was a duplicate of Fig. 1. This has now been amended.

Published online: 14 December 2018

https://doi.org/10.1038/s41559-018-0774-1 